\title{
Mieloma múltiplo em uma cadela de 10 anos
}

\author{
Multiple Myeloma in a 10-year-old Bitch \\ Natália Peixoto Carioca Gurgel', Leonardo Alves Rodrigues Cabral', Maressa Holanda dos Santos', \\ Danilo Galvão Rocha ${ }^{2}$, Talles Monte de Almeida ${ }^{3}$ \& Paula Priscila Correia Costa ${ }^{2,3}$
}

\begin{abstract}
Background: The malignant neoplasms, in general, constitute one of the main causes of death in dogs and cats. The multiple myeloma is a neoplasm characterized by the monoclonal proliferation of plasma cells in the bone marrow, causing several systemic symptoms and it is rare in pets, representing less than $1 \%$ of the malignant neoplasms in these animals. It usually occurs in older dogs. Thus, the purpose of this report was to describe a case of multiple myeloma in a 10-year-old poodle dog, occurred in the Veterinary Hospital Unit of the State University of Ceará.

Case: A 10-year-old Poodle bitch was admitted in the Veterinary Hospital Unit of the State University of Ceará presenting lump erythematosus, alopecic, soft and ulcers in the region of the digits of the left front leg, pain and lameness. The blood count evidenced normocytic and normochromic anemia, presence of rouleaux, lymphopenia and monocytopenia, and the biochemical exams have demonstrated an elevated value of alanine aminotransferase (ALT). The cytology of the nodule indicated probable diagnosis of plasma cell neoplasm and radiographic examination showed the presence of bone lysis, and therefore the patient underwent amputation of the affected limb surgery. A biopsy of the nodule indicated neoplastic proliferation, with an arrange compatible to plasmacytoma of cleaved type. A follow-up consultation was realized 30 days after surgery, and 2 new nodules appeared in the superior lip region and close to the surgery site. A new blood count indicated anemia with presence of rouleaux, thrombocytopenia, leucopenia, lymphopenia and monocytopenia, and the biochemical results showed a discrete diminution of aspartate aminotransferase(AST) and a considerable increase on the alkaline phosphatase levels. The cytology of the new nodules indicated plasmacytoma, and was realized a myelogram, that showed dysplastic marrow plasma cells, with more than $20 \%$ of plasma cells.

Discussion: In the present case, the patient's lump grew rapidly with bleeding and ulcer formation. The animal presented bone involvement, which characterizes the most suggestive sign of multiple myeloma. Justified by the stimulating factor of osteoclasts, promoting bone lysis, which can cause pathological fractures and pain. The amputation was a partial treatment to attenuates the discomfort and pain presented by the patient. The appearance of new nodules stimulated a more detailed investigation for multiple myeloma. The enzyme AST presented a discrete diminution, and ALT initially was higher than normal, but then returned to normal values. So, the elevated activity of alkaline phosphatase directed the suspects to multiple myeloma, since the activity of AST and ALT was normal, the alkaline phosphatase level was ligated to bone diseases. The rouleaux was constant at the hemograms, this is justified by the excess of immunoglobulins produced in marrow. Based on the chart presented by the patient, the bone marrow was punctured for myelogram. The symptoms displayed by the animal along with the cytological analysis, histopathological, hematological, biochemical and with myelogram indicated diagnosis of multiple myeloma. Other exams could be investigated, for example, detection of Bence Jones proteinuria, serum calcium dosage and inmunoelectroforesis for determination of the type of immunoglobulin produced by the plasma cells in the bone marrow. The definitive diagnostic was established approximately three months after the first consult, emphasizing the importance of a multiple myeloma differential diagnostic in case of plasma cell neoplasm.
\end{abstract}

Keywords: plasma cell, monoclonal proliferation, myelogram.

Descritores: plasmócito, proliferação monoclonal, mielograma. 


\section{INTRODUÇÃO}

As neoplasias, de uma maneira geral, constituem uma das principais causas de morte de cães e gatos, sendo de extrema importância o desenvolvimento da investigação para a determinação do tipo de neoplasia encontrado em cada animal, tanto para o estabelecimento da terapêutica necessária, quanto para a documentação científica [2,6].

O mieloma múltiplo é raro, representando menos de $1 \%$ dos casos de neoplasias malignas em cães e gatos [8]. É uma neoplasia caracterizada pela proliferação desregulada e clonal de plasmócitos pela medula óssea, que produzem e secretam imunoglobulinas (Ig) ou fragmentos dessa, chamada de proteína M [5]. A doença pode causar: falência renal, destruição óssea, supressão da hematopoiese e supressão da medula óssea [4]. Além de raças pequenas, pode-se relatar maior ocorrência em cães idosos, com idade entre 8 e 10 anos $[1,7]$. O tratamento padrão indicado é a quimioterapia a base de agentes alquilantes. A cirurgia de ressecção do plasmocitoma extra medular é considerada curativa, tendo, portanto, prognóstico favorável [9]. No entanto, para plasmocitoma solitário ósseo e mieloma múltiplo o prognóstico é definido como reservado [3].

O objetivo do trabalho é relatar e descrever um caso de mieloma múltiplo em cão ocorrido na Unidade Hospitalar Veterinária da Universidade Estadual do Ceará, chamando a atenção para a importância da investigação detalhada dos quadros neoplásicos, a fim de estabelecer um diagnóstico preciso, melhorando a possibilidade de tratamento.

\section{CASO}

Realizou-se atendimento, na Unidade Hospitalar Veterinária da Universidade Estadual do Ceará (UHV-UECE), de um animal da espécie canina, do sexo feminino, raça Poodle, pelagem branca, 10 anos de idade, pesando 4,5 kg e não castrada (Figura 1A). O proprietário relatou surgimento de nódulo avermelhado em membro anterior esquerdo, na região dos dígitos, de crescimento rápido (em torno de 30 dias) [Figura 1B]. Além desta queixa, constatou-se a presença de neoformação na altura das glândulas mamárias abdominais caudais. Observou-se estado geral de obnubilação com lateralização da língua, dificuldade de deambulação e dor no membro afetado. À palpação, os linfonodos poplíteos se apresentavam infartados. Os demais parâmetros encontravam-se inalterados. Tendo em vista as alterações, foram solicitados hemograma completo, dosagens bioquímicas séricas e radiografias para fins de diagnóstico.

O hemograma evidenciou anemia normocítica e normocrômica, presença de rouleaux eritrocitário, linfopenia $(549 / \mu \mathrm{L})$, monocitopenia $(61 / \mu \mathrm{L})$ e elevada contagem de proteínas totais $(9,8 \mathrm{~g} / \mathrm{dL})$ [Tabela 1]. A análise sérica de enzimas demonstrou valor normal de creatinina, porém com valor elevado de alanina aminotransferase (ALT) (117 UI/L) [Tabela 2]. A punção aspirativa por agulha fina realizada nos dois nódulos encontrados no animal resultou em quadro citopatológico compatível com plasmocitoma nos dígitos do membro anterior esquerdo e adenoma mamário com provável foco de malignidade (Figura 2). A radiografia realizada no membro anterior esquerdo indicou manutenção da relação articular entre úmero, rádio e ulna, com interlinhas radiográficas regulares. No entanto, demonstrou acentuado aumento de volume de partes moles no dorso palmar esquerdo, de radiopacidade e

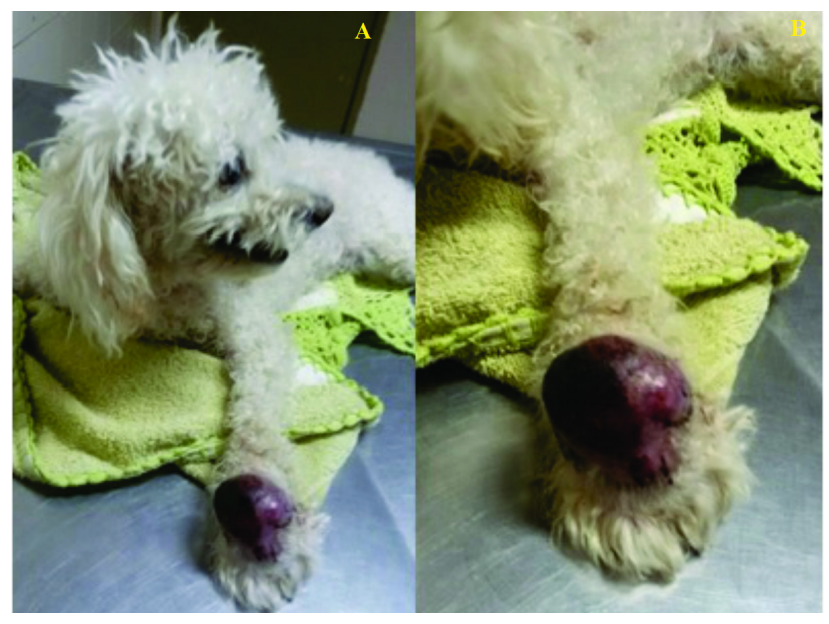

Figura 1. Paciente canina (fêmea, poodle, 10 anos de idade) atendida na Unidade Hospitalar Veterinária da Universidade Estadual do Ceará (A). Nódulo eritematoso e alopécico em dígitos do membro anterior esquerdo em evidência (B).

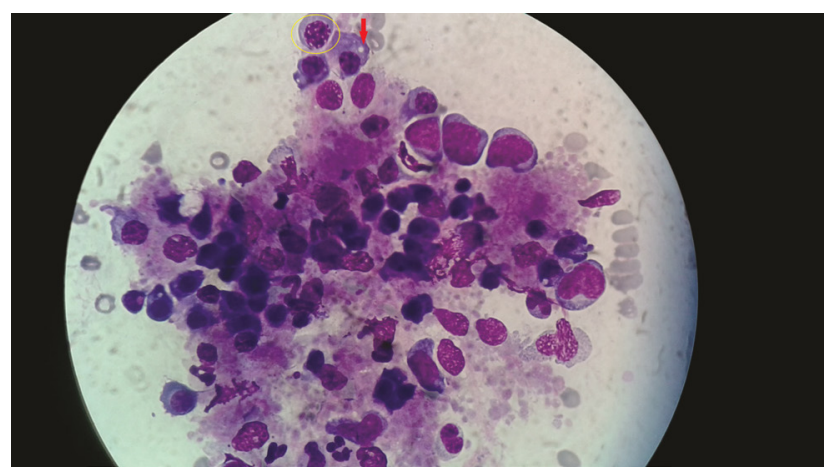

Figura 2. Citologia de linfonodo poplíteo indicando acentuada concentração de células plasmáticas com alterações morfológicas e presença de células de Mott (seta). Células com núcleo de cromatina condensada com eventuais nucléolos múltiplos e evidentes. 
Tabela 1. Parâmetros hematológicos do hemograma realizado no primeiro atendimento, evidenciando anemia normocítica e normocrômica, presença de rouleaux eritrocitário, linfopenia, monocitopenia e hiperproteinemia.

\begin{tabular}{ccc}
\hline Parâmetro & Resultado & Valores de referência \\
\hline Hemácias & $4.900 .000 / \mu \mathrm{L}$ & 1.5 a $8.5 \times 10^{6} / \mu \mathrm{L}$ \\
Hemoglobina & $9,5 \mathrm{~g} / \%$ & 12 a $18 \mathrm{~g} / \%$ \\
Hematócrito & $30 \%$ & 37 a $55 \%$ \\
VCM & $61.2 \mu / \mathrm{m}^{3}$ & 60 a $77 \mu / \mathrm{m}^{3}$ \\
CHCM & $31,6 \%$ & 32 a $36 \%$ \\
Plaquetas & $343.000 / \mu \mathrm{L}$ & 200 a $500 \times 10^{3} / \mu \mathrm{L}$ \\
Linfócitos & $09 \%(549 / \mu \mathrm{L})$ & 12 a $30 \%(1.000$ a $4.800 / \mu \mathrm{L})$ \\
Monócitos & $01 \%(61 / \mu \mathrm{L})$ & 03 a $10 \%(150$ a $1.350 / \mu \mathrm{L})$ \\
PPT & $9,8 \mathrm{~g} / \mathrm{dL}$ & 6,0 a $8,0 \mathrm{~g} / \mathrm{dL}$ \\
\hline
\end{tabular}

limites não definidos; ausência de ossos metacarpais II, III, IV e das falanges proximais do segundo, terceiro e quarto dedos esquerdos e presença de lise óssea nos ossos do carpo esquerdo (Figura 3). Com base nos resultados obtidos nos exames, principalmente a citologia da neoformação do membro anterior esquerdo, chegou-se ao diagnóstico de plasmocitoma ósseo.

Tabela 2. Resultados das dosagens bioquímicas de creatinina, com valor dentro dos limites de referência; e ALT, evidenciando valor elevado.

\begin{tabular}{ccc}
\hline Parâmetro & Valor encontrado & Valor de referência \\
\hline Creatinina & $0,5 \mathrm{mg} / \mathrm{dL}$ & 0,5 a $1,5 \mathrm{mg} / \mathrm{dL}$ \\
ALT/TGP & $117 \mathrm{UI} / \mathrm{L}$ & 21 a $102 \mathrm{UI} / \mathrm{L}$ \\
\hline
\end{tabular}

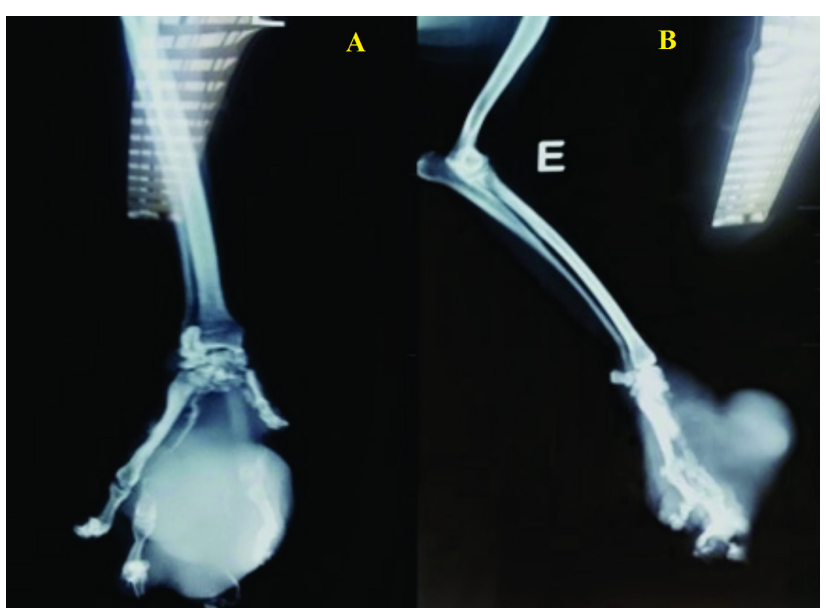

Figura 3. Imagens radiográficas do membro anterior esquerdo, nas projeções médio-lateral (A) e dorso-palmar (B), indicando acentuado aumento de volume de partes moles no dorso palmar esquerdo, de radiopacidade e limites não definidos; ausência de ossos metacarpais II, III, IV e das falanges proximais do segundo, terceiro e quarto dedos esquerdos e presença de lise óssea nos ossos do carpo esquerdo.
A segunda avaliação da paciente foi realizada 30 dias após a primeira consulta, de acordo com a disponibilidade do proprietário. Na ocasião, o nódulo localizado nos dígitos havia aumentado de tamanho e apresentava sangramento constante, com aumento da dor por parte do animal. Optou-se pela realização de cirurgia de amputação do membro afetado com objetivo de diminuição da dor e como parte do tratamento do plasmocitoma.

Foi solicitada a realização de exames para avaliação da função cardíaca do animal. O ecodopplercardiograma identificou: hipertrofia ventricular esquerda (tipo concêntrica) de grau discreto; dilatação arterial esquerda de grau leve a moderado; dilatação atrial direita de grau leve; leve refluxo de tricúspide; insuficiência mitral leve e escape aórtico e pulmonar. O eletrocardiograma indicou: arritmia sinusal, aumento do átrio esquerdo, sugestivo aumento de ventrículo esquerdo e presença de áreas de hipoxia do miocárdio. A aferição da pressão arterial teve como valor obtido aproximadamente 140 x $80 \mathrm{mmHg}$, evidenciando discreto aumento da pressão arterial. A radiografia de tórax permitiu visualizar discreto aumento de silhueta cardíaca em correspondência às câmaras cardíacas esquerdas; opacidade de campos pulmonares, em lobos caudais, de padrão radiográfico intersticial tendendo a alveolar; não sendo visualizadas imagens compatíveis com nódulos metastáticos no parênquima pulmonar (Figura 4).

A cirurgia ocorreu 40 dias após o primeiro atendimento. A técnica cirúrgica escolhida foi a de 


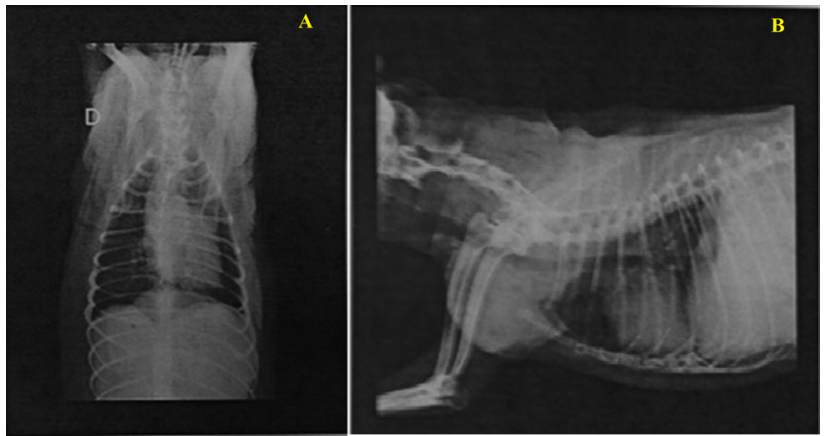

Figura 4. Imagem radiográfica do tórax na projeção ventro-dorsal (A) e na projeção latero-lateral esquerda (B), sendo visualizado discreto aumento de silhueta cardíaca em correspondência às câmaras cardíacas esquerdas; opacidade de campos pulmonares, em lobos caudais, padrão radiográfico intersticial tendendo a alveolar; sem imagens compatíveis com nódulos metastáticos no parênquima pulmonar.

amputação por meio de ressecção na porção medial do úmero. Após o procedimento, a peça contendo o nódulo plasmocitário foi encaminhada para realização de biópsia. $\mathrm{O}$ animal teve alta no mesmo dia. A medicação oral prescrita para os dias seguintes foram cefalexina (Petsporin $\left.{ }^{\circledR}\right)^{1}\left[30 \mathrm{mg} . \mathrm{kg}^{-1} \mathrm{PO}\right.$ q12 h durante 10 dias], meloxicam $\left(\text { Maxicam }{ }^{\circledR}\right)^{2}[0,05$ mg.kg-1 $\mathrm{q} 24 \mathrm{~h}$ durante 4 dias $]$ e tramadol $\left(\text { Cronidor }^{\circledR}\right)^{3}\left[2\right.$ mg.kg-1 q12 $^{-12}$ h durante 5 dias].

Após quatro dias da cirurgia, realizou-se acompanhamento do animal. Segundo informações do proprietário, este se adaptou adequadamente a ausência do membro, realizando todas as atividades normais que faziam parte de sua rotina, e alimentava-se normalmente.

A biópsia do nódulo indicou proliferação neoplásica não encapsulada, localmente infiltrativa ao tecido conectivo, composta por células redondas dispostas em grupos celulares caracterizados por citoplasma com limites definidos, basofílicos na coloração Giemsa, moderada anisocitose, núcleo redondo a clivado ou identado, cromatina vesicular, moderada anisocariose. Presença de células bi a multinucleadas, nucléolo, por vezes, conspícuo e único. Observado quatro mitoses por campo (aumento de $400 \mathrm{x}$ ). Septos de tecido conjuntivo separam os grupos celulares. Tal arranjo é compatível para a classificação de plasmocitoma do tipo clivado.

Passados 30 dias do procedimento cirúrgico (70 dias do primeiro atendimento), foi realizada nova consulta de acompanhamento, quando foram localizados dois novos nódulos pequenos (em torno de 0,5 $\mathrm{cm}$ ), eritematosos, macios e alopécicos, localizados na região do lábio superior, no lado esquerdo, e na região acima da ferida cirúrgica (Figura 5 A \& B).

Na ocasião, realizaram-se novos exames. Os resultados obtidos no hemograma indicaram anemia (4.290.000 hemácias/ $\mu \mathrm{L}$ de e $8,7 \mathrm{~g} / \%$ de hemoglobina) com presença de rouleaux eritrocitário, trombocitopenia (36.000 plaquetas/ $\mu \mathrm{L})$, leucopenia (4.400 leucócitos/ $\mu \mathrm{L}$ ), linfopenia (572 linfócitos $/ \mu \mathrm{L})$, monocitopenia (132 monócitos/ $\mu \mathrm{L}$ ) e elevada contagem de proteínas totais $(9,2 \mathrm{~g} / \mathrm{dL})$. Não foram observados hematozoários na amostra de sangue do paciente (Tabela 3 ). As dosagens bioquímicas evidenciaram discreta diminuição de aspartatoaminotransferase (AST) [21 UI/L] e de albumina sérica $(2,3 \mathrm{~g} / \mathrm{dL})$ e aumento considerável no valor de fosfatase alcalina (185 UI/L) [Tabela 4]. A análise citológica dos nódulos recém-surgidos indicou quadro citopatológico compatível com plasmocitoma, sendo

\begin{tabular}{ccc}
\multicolumn{3}{l}{$\begin{array}{l}\text { Tabela 3. Resultados obtidos no segundo hemograma, indicando anemia com presença de rouleaux } \\
\text { eritrocitário, trombocitopenia, leucopenia, linfopenia, monocitopenia e hiperproteinemia. }\end{array}$} \\
\hline Parâmetro & Resultado & Valores de referência \\
\hline Hemácias & $4.290 .000 / \mu \mathrm{L}$ & 1,5 a $8,5 \times 10^{6} / \mu \mathrm{L}$ \\
Hemoglobina & $8,7 \mathrm{~g} / \%$ & 12 a $18 \mathrm{~g} / \%$ \\
Hematócrito & $26 \%$ & 37 a $55 \%$ \\
Plaquetas & $36.000 / \mu \mathrm{L}$ & 200 a 500 x $10^{3} / \mu \mathrm{L}$ \\
Leucócitos totais & $4400 / \mu \mathrm{L}$ & 6000 a $17.000 / \mu \mathrm{L}$ \\
N. segmentados & $81 \%(5.368 / \mu \mathrm{L})$ & 60 a $77 \%(3.000$ a $11.500 / \mu \mathrm{L})$ \\
Linfócitos & $13 \%(549 / \mu \mathrm{L})$ & 12 a $30 \%(1.000 \mathrm{a} 4.800 / \mu \mathrm{L})$ \\
Monócitos & $3 \%(61 / \mu \mathrm{L})$ & 3 a $10 \%(150$ a $1.350 / \mu \mathrm{L})$ \\
PPT & $9,2 \mathrm{~g} / \mathrm{dL}$ & 6 a $8 \mathrm{~g} / \mathrm{dL}$ \\
\hline
\end{tabular}


Tabela 4. Resultados obtidos a partir de exames séricos bioquímicos, evidenciando discreta diminuição de AST e de albumina sérica e aumento considerável no valor de fosfatase alcalina.

\begin{tabular}{ccc}
\hline Parâmetro & Valor encontrado & Valor de referência \\
\hline Creatinina & $0,7 \mathrm{mg} / \mathrm{dL}$ & 0,5 a $1,5 \mathrm{mg} / \mathrm{dL}$ \\
ALT/TGP & $61 \mathrm{UI} / \mathrm{L}$ & 21 a $102 \mathrm{UI} / \mathrm{L}$ \\
Uréia & $29 \mathrm{mg} / \mathrm{dL}$ & 21,4 a $59,92 \mathrm{mg} / \mathrm{dL}$ \\
AST/TGO & $21 \mathrm{UI} / \mathrm{L}$ & 23 a $66 \mathrm{UI} / \mathrm{L}$ \\
Fosfatase alcalina & $185 \mathrm{UI} / \mathrm{L}$ & 20 a $156 \mathrm{UI} / \mathrm{L}$ \\
Colesterol total & $178 \mathrm{mg} / \mathrm{dL}$ & 135 a $270 \mathrm{mg} / \mathrm{dL}$ \\
Albumina & $2,3 \mathrm{~g} / \mathrm{L}$ & 2,6 a $3,3 \mathrm{~g} / \mathrm{L}$ \\
\hline
\end{tabular}

recomendada a avaliação de medula óssea objetivando diagnóstico de mieloma múltiplo.

O mielograma foi realizado após quinze dias da detecção dos novos nódulos, assim como um novo hemograma, contagem de reticulócitos, análise bioquímica de uréia, creatinina, ALT, FA, albumina e globulina e PAAF do linfonodo poplíteo esquerdo. O hemograma e a contagem de reticulócitos indicaram anemia arregenerativa, rouleaux eritrocitário, discreta hipocromia, discreta anisocitose com macrócitos e micrócitos, aumento da contagem de neutrófilos seg-

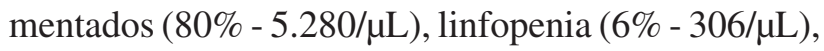
eosinofilia $(0 \%)$, monocitose $(12 \%)$, proteínas elevadas $(9,2 \mathrm{~g} / \mathrm{dL})$, presença de $42 \%$ monócitos ativados e de $17 \%$ linfócitos reativos. Os valores das análises bioquímicas apresentaram diminuição da concentração de ureia sérica $(17 \mathrm{mg} / \mathrm{dL})$, aumento na concentração de albumina sérica (4 g/L) e aumento na taxa de globulina $(5,2 \mathrm{~g} / \mathrm{L})$. A PAAF realizada no linfonodo poplíteo esquerdo evidenciou reatividade e presença de células plasmocíticas. De acordo com a análise da medula óssea, observou-se hiperplasia megacariocítica, hipoplasia granulocítica com granulopoiese neutrofílica eficiente, hipoplasia eritroide com eritropoiese

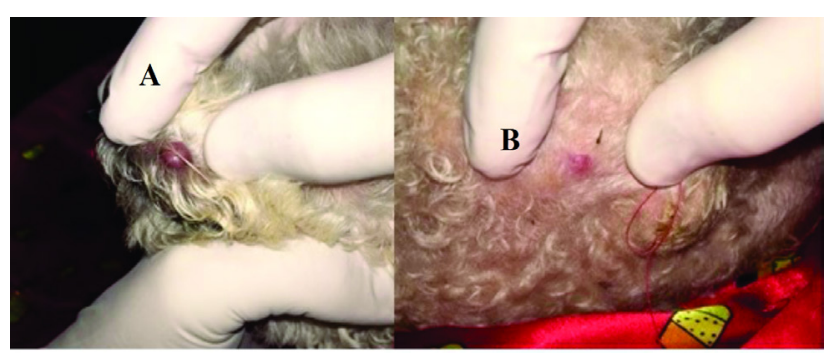

Figura 5. Nódulos pequenos (em torno de $0,5 \mathrm{~cm}$ ), eritematosos, macios e alopécicos, localizados na região do lábio superior, no lado esquerdo (A), e na região acima da ferida cirúrgica (B). ineficiente e plasmocitose medular com mais de $20 \%$ de plasmócitos com direcionamento clínico patológico para mieloma múltiplo. O proprietário optou por não realizar o tratamento do animal e apenas realizar acompanhamento para medidas paliativas.

\section{DISCUSSÃO}

No referido caso clinico, o crescimento do nódulo se deu de maneira rápida apresentando ulceração e sangramento. Os nódulos plasmocitários têm características compatíveis com as encontradas na paciente: macio, alopécico, liso, saliente e ulcerado [7]. Além das características do nódulo, outros sintomas foram relatados de maneira a guiar o diagnóstico definitivo de mieloma múltiplo. O comprometimento ósseo encontrado pode ser descrito como o mais sugestivo de mieloma múltiplo [10], tendo sido acompanhado por dor e claudicação $[6,8]$. A justificativa para tal sintoma é a produção de fator estimulante de osteoclastos promovendo lise óssea e, por consequência, fraturas patológicas e dor $[8,10]$.

A amputação foi realizada como medida de tratamento parcial, de diminuição da dor e do desconforto apresentados pelo paciente. A biópsia da peça indicou nódulo de células plasmocitárias classificado como clivado, onde se encontra anisocitose e núcleos clivados, além de septo fibroso separando o tumor em grupos celulares e infiltração do tecido conjuntivo.

O surgimento de novos nódulos plasmocitários estimulou a investigação detalhada a respeito de mieloma múltiplo. Foram realizados novos exames de hemograma e análises bioquímicas do soro cujos resultados indicaram anemia persistente, trombocitopenia, diminuição considerável do número de leucócitos, aumento do número de neutrófilos segmentados 
e linfócitos e valor constante elevado de proteínas totais. A creatinina e a ureia se mantiveram dentro dos padrões normais indicando função renal preservada. A AST apresentou discreta diminuição, no entanto sem grandes considerações. A ALT, que inicialmente se encontrava acima da concentração normal, retornou a um valor dentro dos parâmetros. Porém a fosfatase alcalina demonstrou valor elevado o que direcionou ainda mais as suspeitas por mieloma múltiplo já que o aumento desta enzima se encontra diretamente ligada a doenças ósseas generalizadas, podendo-se diferenciar esta afecção de afecções hepáticas pelo fato de as demais enzimas hepáticas não estarem alteradas.

Outro parâmetro constante nas primeiras avaliações hematológicas foi o rouleaux eritrocitário, justificado pelo excesso de imunoglobulinas produzidas na medula [10]. Leucopenia e trombocitopenia são fatores explicados pela substituição de células sanguíneas por células neoplásicas na medula óssea e pela destruição plaquetária mediada por excesso de imunoglobulinas produzidas pelas células neoplásicas $[8,10]$.

A grande variedade de sintomas apresentados se dá justamente por essa substituição difusa das células sanguíneas por células neoplásicas plasmocitárias e pela produção exacerbada de imunoglobulinas, espalhando sintomas imunomediados por todo o corpo [6]. Dentre eles a piodermite persistente e a Insuficiência Cardíaca apresentadas pelo animal do relato $[6,8,10]$.

Baseado em todo o quadro sintomatológico apresentado pelo paciente, realizou-se punção de medula óssea para mielograma, além de novos exames hematológicos para acompanhamento, como indicado por Meuten [6].

A partir de nova avaliação, a anemia e o rouleaux eritrocitário continuaram presentes. Foi observada discreta anisocitose com macrócitos e micrócitos e discreta hipocromia, além de a contagem de reticulócitos determinar anemia arregenerativa. Porém a contagem de plaquetas e de leucócitos retornou para o intervalo normal. Os neutrófilos segmentados se apresentaram diminuídos, assim como no primeiro hemograma realizado. Encontrou-se 17\% de linfócitos reativos e $42 \%$ de monócitos reativos. As proteínas plasmáticas totais também permaneceram elevadas, fator comum em animais portadores de neoplasias.

De acordo com as análises bioquímicas do soro, a concentração da Ureia apresentou-se diminuída, não sendo estabelecida justificativa para esse fato. A
FA retornou ao intervalo considerado normal, porém as proteínas Albumina e Globulina se apresentam com um valor acima do esperado para a espécie, sendo explicado pela produção elevada de imunoglobulinas pelos linfócitos B envolvidos no MM [10]. A definição exata das classes de globulina responsáveis pelo aumento de sua concentração sérica deve ser realizada através de técnicas de eletroforese do soro ou da urina, no entanto tal avaliação não pôde ser realizada devido a disponibilidade laboratorial.

A sintomatologia e os achados laboratoriais apresentados pelo animal - lise óssea, insuficiência cardíaca, piodermite recorrente, imunodeficiência, proteínas totais elevadas, anemia arregenerativa e FA elevada - estão de acordo com as descrições da literatura $[6,8,10]$.

Outros exames poderiam ser acrescentados como a detecção de proteinúria de Bence Jones, dosagem de Cálcio sérico e imunoeletroforese para determinação do tipo de imunoglobulina produzida pelos plasmócitos na medula $[6,8]$.

O diagnóstico definitivo foi estabelecido em torno de três meses depois do primeiro atendimento, ressaltando a importância de se considerar o mieloma múltiplo como um diagnóstico diferencial em casos de neoplasia de células plasmocitárias a fim de estabelecer um diagnóstico mais rapidamente visando uma melhor sobrevida do paciente. Não foi estabelecido protocolo de quimioterapia conforme opção do proprietário, que decidiu apenas acompanhar e tratar os sintomas e a dor do animal.

O caráter raro do mieloma múltiplo não deve excluí-lo das investigações clínicas, uma vez que o rápido diagnóstico e seguido tratamento podem melhorar as condições de sobrevida do paciente acometido. Ressalta-se a importância de exames como PAAF, biópsia e mielograma no diagnóstico definitivo de neoplasias como um todo, além de exames complementares que permitam avaliar as condições gerais do paciente visando uma melhor resposta à terapêutica instituída ou ao controle paliativo dos sintomas.

\section{MANUFACTURERS}

${ }^{1}$ Mundo Animal Laboratorio Veterinário Ltda. Pindamonhangaba, SP, Brazil.

${ }^{2}$ Ourofino Pet Saúde Animal. Osasco, SP, Brazil.

${ }^{3}$ Agener União Saúde Animal. São Paulo, SP, Brazil.

Declaration of interest. The authors report no conflicts of interest. The authors alone are responsible for the content and writing of the paper. 


\section{REFERENCES}

1 Abreu T.G.M., Sampaio G.R., Wouters F., Rios P.B.S. \& Oliveira A.K. 2013. Plasmocitoma Em Cão: Diagnóstico e Perspectivas Terapêuticas - Relato de Caso. In: XXII Congresso de Pós-Graduação da UFLA (Lavras, Brasil). pp.1-6. 2 Abreu C.B., Nogueira R.B., Oliveira L.E.D., Paiva F.D., Lacreta Júnior A.C.C. \& Seixas J.L. 2016. Mieloma Múltiplo em Cão. Acta Scientiae Veterinariae. 44(1): 1-5.

3 Fighera R.A., Silva M.C., Brum J.S., Graça D.L., Kommers G.D., Irigoyen L.F. \& Barros C.S.L. 2008. Causas de morte e razões para eutanásia de cães da Mesorregião do Centro Ocidental Rio-Grandense. Pesquisa Veterinária Brasileira. 28(4): 223-230.

4 Hahn K.A. 2002. Veterinary Oncology. 4th edn. Philadelphia: Butterworth-Heinemann. 279p.

5 Kyle R.A., Gertz M.A., Witzig T.E., Lust J.A., Lacy M.Q., Dispenzieri A., Fonseca R., Rajkumar S.V., Offord J.R., Larson D.R., Plevak M.E., Therneau T.M. \& Greipp P.R. 2003. Review of 1027 patients with newly diagnosed multiplemyeloma. Mayo Clinic Proceedings. 78(1):21-33.

6 Mangan P. 2005. Recognizing multiple myeloma. Nurse Practitioner. 30(3): 14-27.

7 Meuten D.J. 2002. Tumors in Domestic Animals. 4th edn. Ames: Iowa State Press, 788p.

8 Morris J. \& Dobson J. 2007. Oncologia em pequenos animais. São Paulo: Roca, 312p.

9 Pinho M.C. 2008. Mieloma múltiplo associado à produção de IgG em cão: relato de caso. 19f. Rio de Janeiro, RJ. Monografia (Pós-graduação Latu sensu em Patologia Clínica) - Universidade Castelo Branco.

10Slatter D.B.V. 2007. Manual de cirurgia de pequenos animais. Barueri: Manole, 2896p.

11 Withrow S.J. 2007. Why Worry About Cancer in Pets? In: Withrow S.J \& Macewen E.G. (Eds). Small Clinical Veterinary Oncology. 5th edn. St Louis: Elsevier, pp.XV-VXII. 